\title{
No Waste by 2010: leading the way
}

\author{
C. Horsey \\ ACT NOWaste, Department Urban Services, \\ Australian Capital Territory (ACT) Government, Australia
}

\begin{abstract}
The Government of the Australian Capital Territory (ACT) was the first in the world to establish a No Waste by 2010 Goal in 1996 and has since established itself as an international leader in sustainable waste management practices. The No Waste Strategy is the result of extensive community consultation, which identified a strong community desire to achieve a waste-free society by 2010 . Since its inception, the No Waste goal has had strong government and community backing and support that has resulted in significant changes in the way waste is viewed and handled in our community.

Implementation of the No Waste Strategy has already achieved a resource recovery rate of over $73 \%$, with some 550,000 tonnes of resources being recovered and processed out of the 770,000 tonnes of waste generated in the Territory annually. This $73 \%$ resource recovery rate has been achieved despite a steady increase in total waste generation that is linked to increasing consumption patterns of an affluent western society.
\end{abstract}

The No Waste Strategy is based on the implementation of an Integrated Resource Recovery Approach that incorporates: the use of economic mechanisms; provision of appropriate infrastructure and services; strategic partnerships and alliances; the development of a resource recovery industry within the ACT; market development for products derived from wastes; strong community engagement programs; and recognition mechanisms for No Waste leaders in our community. Importantly, legislation and regulation mechanisms have not been utilised at this stage to drive resource recovery outcomes.

The model is based on four distinct corner stones:

- The recovery of standard recyclable materials from both the residential and business sectors;

- The recovery and processing of mixed building and demolition wastes and mixed commercial and industrial wastes;

- The recovery, separation and processing of organic materials, with separate processes for garden and food wastes; and

- Then dealing with the more complex composite residual waste products that make up about $5 \%$ of our waste stream.

The paper outlines the Integrated Resource Recovery Model and the approaches that have been adopted for the ACT context; model rationale and details on mechanisms utilised; a progress report; successes and challenges and our future directions.

Keywords: Australian Capital Territory; No Waste; sustainable waste management; Integrated Resource Recovery Approach; resource recovery industry; waste minimisation strategy. 


\section{Introduction}

Many jurisdictions around the world have established waste minimisation targets in varying forms. These targets will deliver a range of differing outcomes due to the policy directions that result from their implementation. The Australian Capital Territory's (ACT's) No Waste by 2010 Policy is significant in that is guiding a philosophy of not only creating a resource recovery culture and developing alternatives to landfilling but is also striving to eliminate landfill activities.

In 1996 the ACT Government was the first in the world to establish the ambitious goal of the "No Waste by 2010" target and policy. This made it the first government to formalise a policy direction towards recovering all resources from the waste stream, with the aim of eliminating landfill. The impacts of establishing such a policy have been far reaching, and include:

- Residents, businesses and government agencies changing their waste practices;

- Waste service providers re-orientating from waste transport and disposal operations to sorting and recovering wastes;

- Development controls established for building design, demolition, construction and operational stages;

- Ongoing, broad scale, and strong political and community support for the No Waste initiatives; and most importantly

- A sense of community ownership and pride in our directions and success.

\subsection{The Australian Capital Territory (ACT) Context}

The ACT is seat of Australia's Federal Government and occupies a catchment area of 2,358 square kilometres with a population of 325,000 people and 125,000 households. The ACT gained self-government in 1989 as a Territory and is governed by a single tier of government that integrates both local and state government functions. This is a unique situation in the Australian context where all other States, and the Northern Territory, have a two tiered government system of separated local and state functions. This means that the ACT has greater control over its waste management legislation, polices and practices through ACT NOWaste (a section of the Department of Urban Services), thus enabling better coordination and delivery of waste management services and minimisation programs.

The ACT is positioned to be the first jurisdiction in the world to achieve a No Waste goal. There are a number of factors that will contribute to such an achievement including:

- Low levels of heavy industry, with the main industries in the ACT being government (Federal and ACT) and the service sector;

- A waste stream with a high percentage of readily recyclable materials;

- The Canberra community seeing itself as a "bush capital" with a clean and green image; 
- A highly educated and environmentally / socially aware population; and

- Strong government and community support for the No Waste Strategy and sustainability in general.

\subsubsection{Waste streams in the ACT}

The ACT total waste to landfill stream is broken down into waste materials delivered from the commercial and industrial sector $(48 \%)$, households $(39 \%$ (with 29\% from domestic collections and 10\% privately delivered) and the construction and demolition sector $(13 \%)$.

The majority of the ACT waste stream is composed of readily recyclable materials, with waste composition data indicating that a total of $95 \%$ of the waste stream is recoverable as valuable resources (APrince [1]). The remaining 5\% is made up of what have been termed complex composite or problematic materials. These wastes are composed of a range of material types that are complex to separate into recyclable materials or are made from materials that for some reason are not readily recyclable. Problematic wastes such as tyres, computers, and electrical items belong to this group.

It is important to distinguish that No Waste has not been interpreted to mean zero waste to landfill. Rather it is more about the action of not wasting resources and preventing valuable resources from being landfilled. In the ACT, with such a high percentage of the waste stream being readily recyclable, a benchmark of achieving a 95\% resource recovery rate has been established, leaving 5\% of residual waste materials requiring landfill disposal as at 2010. With a focus at a national level on establishing national industry agreements covering extended producer responsibility, product design and whole of lifecycle assessments, it is anticipated that this $5 \%$ residual waste will also be further reduced in the longer term.

\subsubsection{Readily recyclable materials}

Within the ACT there are recycling options that currently exist for the following materials:

- Paper

- Cardboard

- Glass

- Aluminium and steel

- Other metals

- Liquid paperboard

- PET, HDPE and mixed plastics

- Garden/vegetation

- Wood/timber

\section{Progress to date}

Over the past 10 years, the ACT has steadily increased its resource recovery rates with more and more materials being diverted from landfill into repair, reuse and
- Motor and cooking oils

- Soils/rocks

- Plasterboard

- Concrete, bricks, tiles

- Textiles (limited to clothing/rags)

- Reusable (including furniture, fixtures, fittings, electrical etc) 
recycling operations. Over 550,000 tonnes of material are currently being recycled per year in resource recovery operations and this industry continues to grow with many new businesses being established and over 300 jobs being created in this fledgling sector.

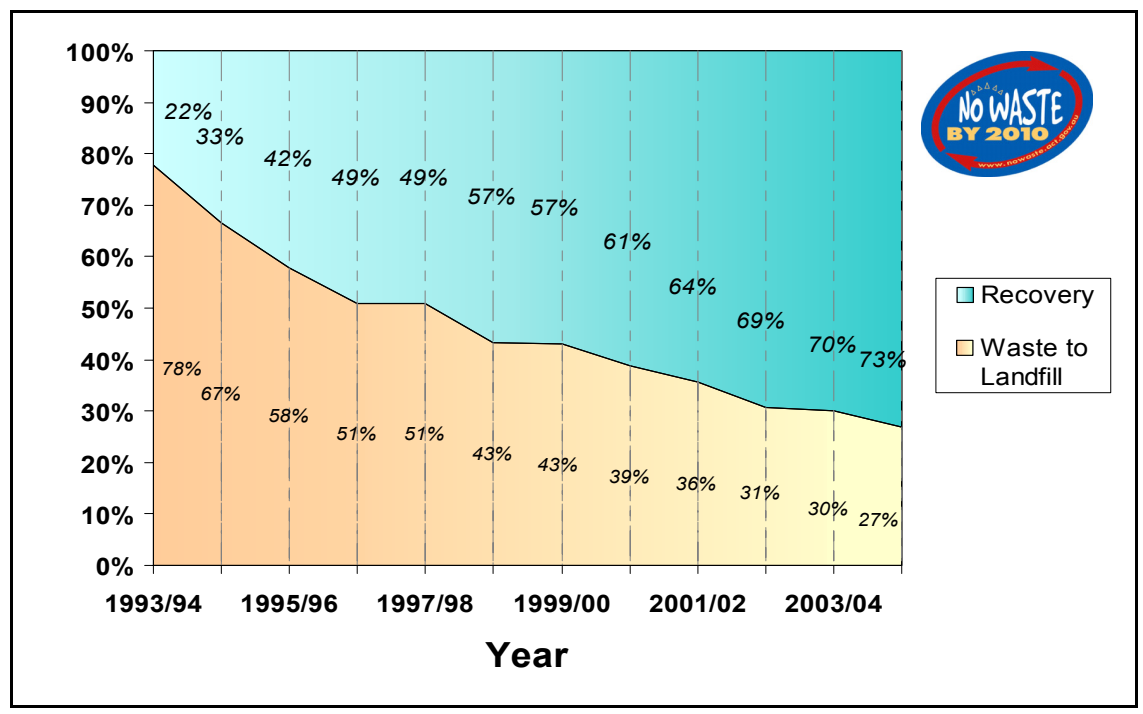

Figure 1: $\quad$ ACT Waste to landfill and resource recovery trends.

The ACT is currently achieving a $73 \%$ resource recovery rate from the total waste stream in the Territory. That is, 550,000 tonnes of resources were recovered from the total waste stream of 750,000 tonnes during 2004-2005. This result has been achieved despite ongoing significant increases in total waste generation within the jurisdiction, as can be seen in Figure 2.

Figure 2 illustrates the significantly increased resource recovery rates that have been achieved in the ACT over the past decade. It also shows that while an initial rapid reduction in waste to landfill has occurred, this has stabilised over the past five years. The reason for this stabilisation trend is that while higher rates of resource recovery $(73 \%)$ have been achieved, total waste generation levels have also increased and kept pace, resulting in a slowing of the reduction of waste to landfill. It is worth noting that if lower resource recovery rates had been achieved then waste to landfill would have significantly increased rather than coming down by almost $20 \%$.

\subsection{The consumption pattern problem}

Sustainability has now become a global mission with all levels of government and the private sector searching for valid ways to meet this challenge. In the waste management arena, many have adopted a waste hierarchy of Avoid, Reuse, Recycle and Disposal as a set of priority actions in order of effectiveness in 
minimising waste. The importance of managing waste once it has been generated is balanced by the need to avoid creating it in the first place. However with a globally dominant paradigm of economic growth and a culture of consumption, it is worth questioning if Australian society is in conflict with waste minimisation goals, particularly waste avoidance.

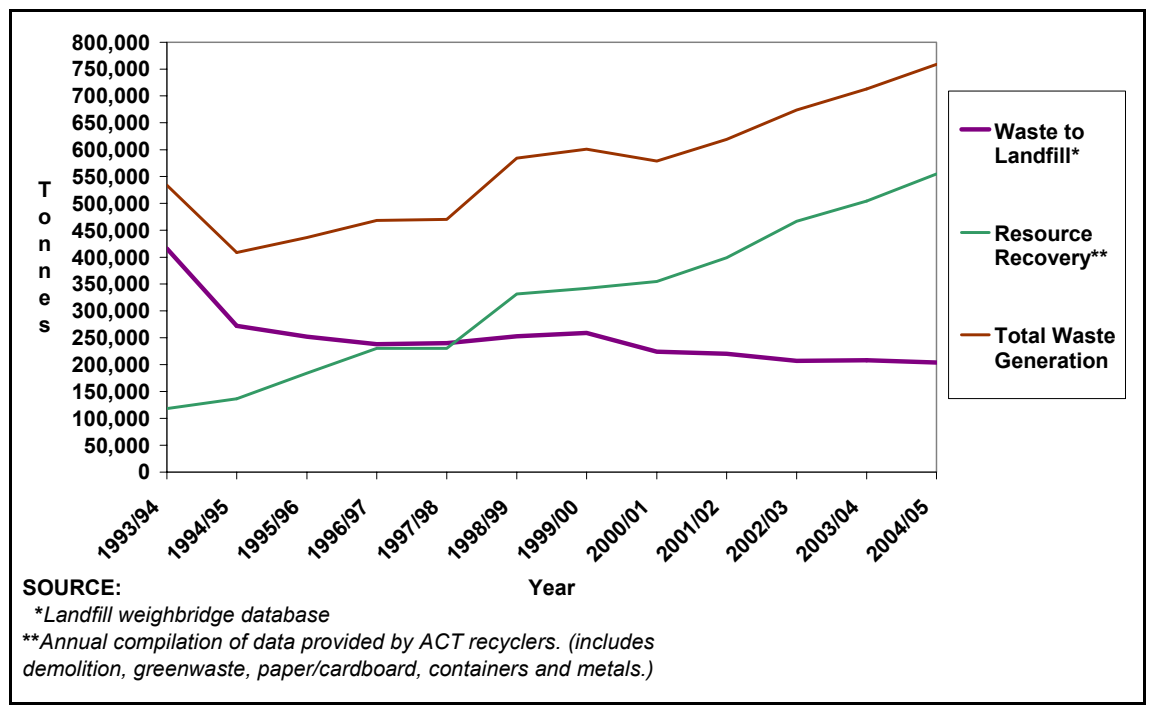

Figure 2: Waste generation, waste to landfill and resource recovery in the ACT.

Fifty years of 'consumption' brainwashing need to be undone. The 1950s gave birth to an 'out with the old and in with the new' philosophy that in the late 1900s and early 2000s has grown into full blown consumerism - buying for the sake of buying. In the 1950s, marketing consultant, Victor Lebow pushed for an increased focus on consumption for the post war US: "Our enormously productive economy...demands that we make consumption a way of life, that we convert the buying and use of goods into rituals, that we seek our spiritual satisfaction... We need things consumed, burnt up, worn out, replaced and discarded at an ever growing rate..." (Seymour and Giradet [2]).

It is apparent that we have realised this vision.

An Australian think tank, The Australia Institute, recently undertook a study into "Wasteful Consumption in Australia 2005" which has some pertinent findings and reflections on waste generation and consumption patterns:

"Economic growth has become a dominant objective in itself, irrespective of the extent to which it contributes to improving social well-being." (Hamilton et al. [3])

For some, shopping and buying have become activities that give pleasure while actually consuming the goods bought is secondary and may not take place at all. 
According to the results of a 2005 survey commissioned by the Australia Institute, $62 \%$ of Australians believe that they cannot afford to buy everything they really need. It is not just low income earners that feel this way, with $47 \%$ of respondents in the richest $20 \%$ of households believing their incomes are inadequate for their needs (Hamilton et al. [3]).

On average each Australian household wasted A\$1226 on items purchased but unused in 2004. This amounts to over A $\$ 10.5$ billion dollars annually spent on goods and services that are never, or hardly ever, used. Food accounts for the most wasteful consumption. Overall during 2004 Australians threw away A \$2.9 billion of fresh food, $\$ 630$ million of uneaten take-away food, A\$876 million of leftovers, A $\$ 596$ million of unfinished soft drinks and A $\$ 241$ million of frozen foods, a total of A\$5.3 billion on all forms of food. This represents more than 13 times the A\$386 million donated by Australian households to overseas aid agencies in 2003 (ACFID [4]).

Throughout history our leaders have visioned the future and enacted policies and mechanisms to achieve the desired end results. It is clear that whilst we certainly have achieved our consumption and economic objectives, if we are to genuinely move towards a sustainable future we must create a new vision for our society that reconciles consumption patterns with our environmental, social and personal wellbeing needs.

We need to reflect on why our society has ritualised and spiritualised consumption and determine how we can re-engineer this trend in the western world.

\section{The No Waste Strategy}

The No Waste Strategy has been formulated around a number of social change mechanisms that form an available tool box for local and state authorities to use to facilitate waste minimisation. The social change tool box used within the No Waste Strategy development encompasses the following:

- Policy development and implementation;

- Economic and market force mechanisms;

- Infrastructure and service provision (both public and private sector based);

- Market development for waste derived products;

- Community engagement including education, communication, training, direct participation opportunities and consultation processes;

- Strategic partnerships and alliances;

- Research and development;

- Data management and reporting; and

- Awards and recognition of No Waste Leaders within the community.

\subsection{Policy development and implementation}

The impacts of establishing a policy direction such as the No Waste by 2010 policy should not be underestimated. With high profile education, 
communication and marketing campaigns and a range of community engagement programs, the concept of No Waste has been broadly disseminated and, to a large degree, accepted by the community as a means of moving towards sustainability. No Waste is seen as a major arm of sustainability, with energy, water and waste agencies often working side by side on social change programs.

Through mechanisms such as the Waste Service Providers Forum, the waste industry is being engaged and encouraged to respond to the government's policy objective. Other consultative mechanisms such as Waste Forums, have allowed peak industry, environmental and educational groups and associations, such as the Regional Chamber of Commerce and Industry, to become familiar with the No Waste Strategy and to also facilitate member input and feedback on their needs in relation to supporting and implementing waste minimisation.

\subsection{Economic and market force mechanisms}

\subsubsection{Recognising the true cost of waste to landfill}

In 2001 the ACT undertook a study - "The Actual Costs of Waste Disposal in The Act 2001" (RPM Pty Ltd et al. [5]) - to determine the true cost of waste to landfill. Historically only the administrative, contractual and operational costs were considered in setting prices for wastes. The study examined all costs associated with landfill including social, economic and environmental costs. These include: loss of amenity; surrounding land value issues; lost resources and lost opportunity costs; environmental monitoring and protection; remediation and rehabilitation; greenhouse; and the traditional costs of capital works, and operations and service contracts.

The study revealed that the true cost of waste to landfill in the ACT was A $\$ 105$ per tonne. At that time the current waste to landfill charge was $A \$ 35$ per tonne. The ACT subsequently developed a "Waste Pricing Strategy 2002" that recognised that waste generators were being heavily subsidised for disposal of their waste (ACT Government [6]). The pricing strategy set about adjusting the cost of waste to landfill charges in line with true costs over a five-year period to minimise impacts on waste generators, particularly the business sector.

Table 1: $\quad$ Waste to Landfill charges in ACT.

\begin{tabular}{ll}
\hline Year & Waste to landfill charge \\
\hline $2001-02$ & $\mathrm{~A} \$ 33$ \\
\hline $2002-03$ & $\mathrm{~A} \$ 44$ \\
\hline $2003-04$ & $\mathrm{~A} \$ 55$ \\
\hline $2004-05$ & $\mathrm{~A} \$ 66$ \\
\hline $2005-06$ & $\mathrm{~A} \$ 77$ \\
\hline $2006-07$ & $\mathrm{~A} \$ 88$ (proposed) \\
\hline
\end{tabular}

\subsubsection{Market forces create the emergence of resource recovery businesses}

In addition to reflecting the true cost of landfill, a significant driver in the pricing strategy was enabling the emergence of resource recovery alternatives. If wasteto-landfill remained the cheapest option for waste management then establishing 
more costly waste diversion alternatives would result in market failure. The pricing strategy has been successful, with the emergence of new private sector resource recovery businesses in the market-place. These businesses have realised that they can now process waste materials and market the waste-derived products for a cost that out-competes waste to landfill charges. Initially this development occurred in the case of separated construction and demolition materials, including concrete, bricks, tiles, wood waste and the like. However, it has since spread to waste collection companies who now are taking mixed commercial, construction and demolition wastes back to processing facilities and sorting the materials to extract resources.

Waste pricing has been a successful market driven approach to establishing a viable resource recovery industry within the private sector without the investment of public funds for infrastructure and service provision. There have been significant benefits in jobs creation that go beyond the traditional waste industry model of collection and transport to landfill disposal. It is estimated that the growing resource recovery industry has generated over 300 jobs within the ACT region over the past decade. It should be recognised that the extent of this job creation could not have been realised under a traditional waste industry model. Furthermore the salaries and wages derived from these jobs have a positive flow on impact within the local economy.

\subsubsection{Waste generator user pays model}

The pricing strategy also signalled a change in responsibility for covering waste disposal costs. Traditionally, the ACT Government derived rates revenue and commercial fees and charges to partially cover waste management costs with a significant portion of the costs being met from government finances. The pricing strategy changed this situation and transferred waste disposal costs back onto the waste generator in an effort to control waste generation rates. The concept is no different from charging strategies in the utility sectors of water or electricity, where a user pays approach requires consumers to pay for the products they use. The pricing strategy requires waste generators to pay for the wastes they generate if they are require it to be landfilled.

There is a clear incentive for waste generators to now take up cheaper and more sustainable alternatives than waste to landfill disposal. The key message from the government is that: "We don't want people to pay the higher waste disposal costs, we want them to take up recycling and resource recovery alternatives."

As waste disposal costs continue to rise over the next few years it is anticipated that further development of the resource recovery sector will continue with government encouragement and assistance.

\subsubsection{Aligning charges for a future Alternative Waste Treatment Plant}

It is important that the true cost of waste to landfill also aligns with the expected costs of treating waste in an alternative waste treatment (AWT) plant. This will ease the transition between landfill and AWT by minimising the price differential. 


\subsection{Infrastructure and service provision}

The ACT Government is responsible for the provision of certain waste infrastructure and services to the ACT community. It provides a full range of household services, and also operates a regional combined landfill and resource recovery facility for both domestic and commercial waste. The landfill industry is regulated through a central regulation agency, the Environmental Protection Authority, who issues licences for landfilling and waste processing operations. At present there is only one operational landfill run by ACT NOWaste, which accommodates the remaining 204,000 tonnes of waste to landfill. A commercial waste service provider industry exists to provide both waste and recycling services to the business and industry sector of the ACT.

The ACT Government provides a range of household services including a weekly 140 litre wheelie bin garbage service and a fortnightly fully co-mingled 240 litre wheelie bin recycling service. Multi-unit complexes receive similar but shared services using hoppers. Household garbage continues to be disposed of to landfill at present, with the recyclables being processed at a state of the art Materials Recovery Facility (MRF).

\subsubsection{Household hazardous waste collection}

Residents also have access to an on-call household hazardous waste collection service where they can book in for collections of paints, solvents, pesticides, fungicides, petroleum products and other chemicals that divert toxic substances away from landfill for treatment. Permanent drop-off facilities exist for motor and cooking oils, paints, fire extinguishers, gas bottles and car batteries.

\subsubsection{Re-usables}

Residents are able to take re-usable materials from households to one of a number of free drop-off centres where goods are repaired, reconditioned and resold. One of these facilities generates over A $\$ 1$ million in revenue per year. Materials such as furniture, office equipment, electrical items, white goods, kitchen wares, toys, sporting items, tools, and building materials such as doors and window frames are all accepted at these facilities. On the weekends these facilities look like a bustling market place.

\subsubsection{Regional Recycling Drop-off Centres}

Several Regional Recycling Drop-off Centres are strategically located throughout the ACT to enable businesses to recycle a range of materials free of charge. These facilities accept standard recyclables including paper, cardboard, glass, aluminium, steel cans, plastics and liquid paperboard. By far the largest quantity of material recovered is cardboard from the retail sector. Residents with surplus recyclables generated at peak consumption times such as Christmas or when moving can also access these free facilities to recycle materials.

\subsubsection{Garden waste}

Historically in the ACT small 55 litre hand bins were used for household garbage collection and this meant that residents were not able to put their garden waste in 
the household collection system. Residents became accustomed to selftransporting garden waste to a number of free regional garden waste acceptance and processing facilities. This practice has largely continued since the introduction of 140 litre wheelie bins for garbage, with residents delivering garden waste in trailers, utility vehicles and car boots.

The ACT has three major garden waste acceptance and processing facilities that take garden waste materials free of charge from households, businesses and waste service providers. Two of these facilities are under contract to the ACT Government and a third exists as an independent commercial resource recovery operation.

The garden waste is turned into valuable mulches, composts and soil and potting mix products and marketed back into the ACT and interstate. A significant amount of effort has gone into the development of high quality products by the operators and sustainable markets have been developed for all products over the past decade. Over 190,000 tonnes of garden waste is recovered and the products find their way back into Australian soils, adding value in terms of moisture retention, carbon content, microbial activity and improving soil structures, all of which results in enhanced ecosystems either in the urban or rural environment. The value of this organic recycling cannot be underestimated for a country such as Australia that has extremely thin and poor top soils.

There continues to be an estimated 14,000 tonnes of garden waste going to landfill from households, another 2,500 tonnes from businesses and 1,200 tonnes from construction and demolition activities, a total of 17,700 tonnes. With mixed waste sorting beginning to take effect it is anticipated that much of this garden waste material will be separated and diverted into the existing free garden waste processing facilities.

\subsubsection{Construction and demolition waste}

Construction and demolition waste can be taken to two major recycling facilities at cost to the waste generator. One of these facilities operates from within the ACT's landfill facility under contract to the Territory, the other is a commercial resource recovery operator. Both of these facilities accept and process concrete, bricks, tiles, plaster board, wood waste, steel and soils. The facility that operates within the ACT landfill also processes mixed construction and demolition wastes using a range of processing technologies. The processing includes tromels to screen soil products, magnets and eddy currents to remove metals and aluminium, an excavator to separate bulk steel, wood waste, plaster board and plastic wrap and a hand-sort line to separate remaining materials with a small amount of residual waste going to landfill.

\subsubsection{Private sector responding to resource recovery}

There are a number of independent resource recovery operators within the ACT that are accepting and processing waste materials. These businesses have become possible under the waste pricing strategy that has allowed them to now charge reasonable rates to accept, sort, separate and process waste materials at a charge that is still cheaper than sending the material to landfill. Several waste 
collection and transport companies have seized the opportunity to change the nature of their business and align it with the Government's No Waste Policy. This has not only provided a market advantage to them but has also lowered the waste-to-landfill costs of their business which have been used as an offset to establish sorting and processing operations.

\subsubsection{Government assisted Resource Recovery Estates}

Resource Recovery Estates have also been developed by the ACT Government to assist the development of the resource recovery industry within the region. There are two estates, one that serves as an incubator model where businesses can trial or undertake establishment activities to enter the market place and another for larger scale higher infrastructure investment operations. In both estates there is a system of discounting market based licences or sub-leases based on the priority waste materials targeted and the quantity of materials diverted from landfill.

\subsubsection{Responding to possible market failures}

While there has been a strong take-up of recycling services within the business and industry sectors there is still significant room for further take-up. In discussions with peak associations, such as the Chamber of Commerce and Industry, it has become apparent that businesses see recycling as an additional cost. Through further investigation this attitude appears to stem from the fact that business and industry, when approaching waste service providers, generally purchase an additional recycling system that stands alongside of their existing waste systems, resulting in the recycling system being an additional cost impost. It is difficult to pinpoint what is occurring here. Are waste service providers marketing recycling services as a tack-on service to existing waste services to gain maximum profit? Or, have businesses failed to understand that they need to review their waste service arrangements? This would include reducing the size of bins and frequency of waste collection, to deliver a cost savings that in most cases can be off-set against recycling services.

To tackle this problem the government has undertaken a mass-media campaign encouraging business and industry to take up recycling and review their current waste services to downsize them and reduce the frequency of collection. The waste service provider industry has also been encouraged to market their recycling services and to change the range of the services they provide to recover the readily recyclable materials.

ACT NOWaste is currently considering establishing a differential charge of A \$140 per tonne for loads of waste containing greater than $50 \%$ recyclables to landfill to further provide mechanisms to drive the take-up of recycling services. If the market, being both the waste service providers and the business and industry sectors, does not respond over the next 12-24 months then regulations will be introduced under the Waste Minimisation Act 2001 that will require business and industry to establish recycling and waste diversion systems and services. 


\subsection{Market development for waste derived products}

As the resource recovery industry has grown, so too has the need to establish and expand existing markets for waste derived products. This area has been challenging for the ACT due to its limited population and economy base. Further market analysis work is required to examine future directions including forecasting waste-derived material types and quantities, looking at existing market capacities, mapping market gaps and undertaking research and development into waste derived products that will meet prospective user needs.

\subsubsection{Market threats}

There are considerable market threats from other jurisdictions that have differing circumstances to the ACT and may interfere in established markets. For example, Sydney (only 3 hours by road transport) has the capacity to flood markets that the ACT has established with heavily subsidised products on the basis that Sydney processors' revenue is often derived at the acceptance and processing stage, allowing it to forego sales revenue simply to ensure product movement.

\subsubsection{Progressive market development focuses}

The ACT's initial focus for market development activities was centred on garden waste derived products such as mulches, composts, soil products and potting mixes. One of the keys to market development of this material is in ensuring the standard of the products is high and also in tailoring the waste derived product to end users requirements. Approximately $45 \%$ of the ACT garden waste derived products are exported interstate to agricultural activities and also compost and potting mix suppliers.

The ACT NOWaste focus has now moved on to market development for construction and demolition derived products. Markets for wood/timber, concrete, bricks, tiles and steel are well-established, however as the quantities of materials recovered increases there is uncertainty regarding the existing markets' capacities to absorb additional materials.

As the resource recovery industry adapts to cater for mixed waste sorting and separation there is a need to ensure that smaller scale operators have the capacity to find markets for smaller quantities of readily recyclable materials. A significant threat to these smaller scale resource recovery businesses is the loss of a key revenue stream if they cannot realise the market value in the resources recovered within a commodities type market.

\subsection{Community engagement}

Extensive community engagement programs have ensured strong support within the region for the No Waste Strategy, with stakeholders and the broader community taking up the call for action on waste minimisation. ACT NOWaste community engagement programs include:

- Business Waste Reduction Program

- Government Leadership Program 
- Construction and Demolition Waste Reduction Program

- Schools Program

- Public Events Waste Minimisation Program

- Tertiary Students and Volunteers Program

- NOWaste Community Workshops

- Media Coordination Program

- Awards and Recognition Program

- Public Reporting of No Waste Progress

These programs are designed to raise awareness, knowledge and skills to engender positive attitudes and ultimately to change behaviour and practices. This is achieved using a range of social change mechanisms such as communication, education, training, provision of advisory and support services, provision of waste audits and developing waste management plans on a fee-forservice basis.

\subsection{Strategic partnerships and alliances}

The success of the No Waste Strategy requires that the broader community respond to the No Waste Policy and actively take up the challenge of minimising waste in their area of influence. ACT NOWaste has a role in ensuring that a range of strategic partnerships and alliances were established to assist facilitate this objective. Strategic partnerships and alliances have been established with a diverse range of stakeholders including: other relevant government agencies; peak groups and associations; other national and international waste minimisation organisations and agencies; waste industry players; education institutions; Volunteering ACT; and many other organisations.

The benefits of these strategic partnerships and alliances include gaining leverage on social change, increasing the number of No Waste advocates, recruiting specialist expertise and increasing waste knowledge and capacity in the ACT community to name a few.

\subsection{Holding back the legislative and regulatory options}

It is interesting to note that the ACT has achieved its resource recovery progress to-date without the use of any legislative or regulatory mechanisms. The ACT has a Waste Minimisation Act 2001 which has a provision for the creation of Industry Waste Reduction Plans that require selected industries to undertake a range of waste minimisation related actions. At this stage there are no plans to enact this provision and the current cooperative and collaborative approaches stimulated by market forces will continue to be implemented.

\subsection{Integrated Resource Recovery Approach}

A key consideration in the No Waste Strategy approach has been to avoid unnecessary costs imposed on the community. Waste minimisation strategies not only need to be achievable but should also recognise the most economical way to deal with a range of waste types. As No Waste initiatives evolved in the 
ACT, it became clear that diverting different types of waste materials to different processing and treatment technologies would result in the most economical outcomes.

The introduction of the alternative waste management technology industry into Australia was seen by many as a panacea for waste minimisation. This 'black box' solution seemed to mean the simple formula of 'municipal waste in and waste minimisation achievement out' allowed the delivery on ambitious waste minimisation goals. The problem that exists with such a philosophy is that the community, or more specifically waste generators, are paying a premium for waste materials that would be more economically treated if they were separated and diverted to a range of more appropriate treatment options rather than a single facility. This concern for minimising the cost impost on the community has given rise to an Integrated Sustainable Waste Management Approach within the ACT.

The No Waste Strategy is not only setting out to divert waste from landfill but is also mindful of its supporting role within sustainability through defining an Integrated Resource Recovery Approach. This approach views the total waste stream generated from within a region by its sub-streams and selects the most economical treatment processes along with the highest order resource use for the products derived.

The Integrated Resource Recovery Approach is based on:

- Recovery of standard recyclables from both the domestic and commercial and industrial waste streams;

- Processing and recovery of resources from mixed waste from the building and demolition and commercial and industrial sectors;

- Separation, processing and recovery of organic material with separate processes for garden and organic materials;

- Dealing with the more complex composite residual waste materials.

In the ACT there are clear cost differentials that exist between the appropriate processes for the recovery of different waste materials. The table below illustrates typical recovery costs for the various waste streams. These exclude transport costs as it is assumed that this is an inherent cost and is independent of the process the material is delivered to, resource recovery or landfill.

Table 2: $\quad$ Cost of resource recovery for different waste materials.

\begin{tabular}{ll}
\hline Recovery of standard recyclables & A $\$ 40-$ A $\$ 50$ per tonne \\
\hline Recovery of recyclables from mixed waste & A\$50 - A \$70 per tonne \\
\hline Recovery of garden waste resources & A $\$ 5$ per tonne \\
\hline $\begin{array}{l}\text { Recovery of recyclables and organics } \\
\text { from mixed waste, including food waste }\end{array}$ & A\$80 - A $\$ 110$ per tonne \\
\hline
\end{tabular}

The No Waste Strategy has focused on driving materials out of the waste stream through the most economically cost efficient process, rather than rely on a 'one stop shop' AWT plant. This approach will minimise the cost impost on the ACT community however it also relies on the community playing its role to avoid unnecessary costs. 


\subsection{Bio bin trial and a third bin -results and observations}

In 2000-2001 ACT NOWaste conducted a trial for household organic materials using a third bin system. Over 1000 participants were involved in a collection program for food and garden wastes to determine if a clean stream of organics could be derived. The objective was to determine if a cheaper and simpler technology could be relied upon to process a clean organics stream. The third bin system, if introduced would cost around $A \$ 2.5-3$ million per year.

The trial results included a weekly bin presentation result of only $60 \%$, however approximately $90 \%$ of all residents participated in the trial. Contamination rates of the organic collection system were around $10 \%$. However, the problem was that $30 \%$ of organic material was still being left in the garbage bin system (ACT Government [7]). This meant that while a relatively clean organics stream could be diverted to a cheaper treatment facility, the garbage stream containing $30 \%$ organics would still require a more complex and costly treatment process.

Given the fact that a more complex waste treatment technology would still be required to deal with the organic material in the garbage system it was decided not to pursue an organics collection system. Furthermore, given that garden waste materials were being recycled for under $\mathrm{A} \$ 5$ per tonne, the value for money aspects of such a decision were highly questionable.

\section{The challenges ahead}

The No Waste Strategy has been steadily delivering increased resource recovery outcomes with over $73 \%$ of all waste generated in the ACT currently being recovered. Waste generation and consumption patterns continue to be a threat for the full success of the strategy. There is a clear need to break the link between the current economic paradigm and waste generation or, alternatively, for resource recovery to increase at a much more rapid rate to outstrip waste generation increases.

Further expansion of the resource recovery industry is required along with expanded market development activities to ensure the sustainability of resource recovery operations. Increased take-up of standard recycling services will further divert recyclables from landfill and minimise the cost impost on the community. To assist the development and expansion of the resource recovery industry, waste to landfill charges in the ACT will continue to rise until they reach the estimated true cost of waste-to-landfill charge of A $\$ 105$ per tonne.

As the ACT Government draws closer to its benchmark of $95 \%$ resource recovery, an AWT plant will be require to extract any remaining recyclables in the waste stream and to process the residual organics (mostly food wastes) in the domestic and commercial waste stream.

Whilst considerable gains have been made in achieving the No Waste goal, continued political and community support will be required to ensure progress and momentum is not lost in this long term social change agenda of treating wastes as resources. 


\section{References}

[1] APrince Consulting, Canberra Residential Waste Audit, 2004.

[2] Seymour and Giradet, Blueprint for a Green Planet, Dorling and Kindersley, London, 1989

[3] Hamilton, C., Denniss, R., \& Baker, D., Wasteful Consumption in Australia, The Australia Institute Discussion Paper No. 77, 2005.

[4] ACFID, Facts and Figures, Australian Council for International Development, Online http:/www.acfid.asn.au/factsandfigures/ factsandfigures.htm [accessed Dec, 2005].

[5] RPM Pty Ltd, Kenny Lin \& Assoc., and Energy Strategies Pty Ltd, The Actual Costs of Waste Disposal in the ACT, 2001.

[6] ACT Government, Waste Pricing Strategy for the ACT, 2002.

[7] ACT Government, Household Organic Material Collection Trial: Chifley August 2000 - June 2001, 2001. 